\section{Soroprevalência da infecção pelo vírus da Hepatite $B$ em uma prisão brasileira}

\section{Seroprevalence of Hepatitis B virus infection in a Brazilian jail}

Harnoldo Colares Coelho'

Sabrina Alberti Nóbrega de Oliveira"

Juliana Custódio Miguel"

Maria de Lourdes Aguiar Oliveira"

José Fernando de Castro Figueiredo'v

Gleici Castro Perdoná"l'

Afonso Dinis Costa Passos"'

' Departamento de Análises Clínicas, Toxicológicas e Bromatológicas da

Faculdade de Ciências Farmacêuticas de Ribeirão Preto da Universidade de São Paulo

"Laboratório de Referência Nacional de Hepatites Virais do Instituto Oswaldo Cruz - FIOCRUZ

III Departamento de Medicina Social da Faculdade de Medicina de Ribeirão Preto da Universidade de São Paulo

Iv Departamento de Clínica Médica da Faculdade de Medicina de Ribeirão Preto da Universidade de São Paulo

Correspondência: Harnoldo Colares Coelho. Departamento de Análises Clínicas, Toxicológicas e Bromatológicas da Faculdade de Ciências Farmacêuticas de Ribeirão Preto da USP. Av. do Café, s/n - Ribeirão Preto,SP CEP 14040-903. E-mail: harnoldo@usp.br

\section{Resumo}

Esta pesquisa objetivou estimar a prevalência do marcador do HBV e seus fatores de risco na população masculina carcerária da Penitenciária de Ribeirão Preto - SP, Brasil. De 1.030 presidiários, foram sorteados 333 participantes, os quais foram submetidos à aplicação de um questionário e à coleta de sangue, no período de maio a agosto de 2003. Para diagnóstico de exposição ao HBV foi utilizado o ensaio imunoabsorvente de ligação de enzimas (ELISA) para detecção dos marcadores HBsAg, anti-HBsAg e antiHBc total. A prevalência total de infecção pelo HBV nos presidiários foi de 19,5\% $\left(\mathrm{IC}_{95 \%}: 15,2-23,8\right)$. A média de idade dos participantes foi de 30,1 anos. Na análise univariada, a infecção pelo HBV esteve associada à idade acima de 30 anos $(\mathrm{p}<0,001)$, uso prévio de drogas injetáveis $(\mathrm{p}<0,001)$ e compartilhamento de agulhas prévio $(p<0,001)$. Em um modelo multivariado, de regressão logística, a infecção pelo HBV foi associada à idade acima de 30 anos (OR $=3,3: \mathrm{IC}_{95 \%}: 1,8-6.1$ ) e uso prévio de droga injetável (OR = 2,7; $\mathrm{IC}_{95 \%}: 1.9-6.4$ ). Infecção pelo HBV nas prisões representa grave problema de saúde pública, principalmente relacionado à idade acima de 30 anos e uso prévio de drogas injetáveis.

Palavras-chave: Hepatite B. Prisões. Prevalência. Fatores de risco. 


\section{Abstract}

This survey aimed to estimate the prevalence of HBV serological markers and risk factors for this infection in male inmates at the Penitentiary of Ribeirão Preto, State of São Paulo, Brazil. Out of 1030 inmates, a simple random sample of 333 participants answered a questionnaire and had blood samples collected, from May to August 2003. Enzyme-linked immunosorbent assay (ELISA) was used to diagnose HBV infection (HBsAg, anti-HBsAg, and total anti-HBc). The overall prevalence for HBV markers in inmates was $19.5 \%\left(\mathrm{CI}_{95 \%}\right.$ : $\left.15.2-23.8\right)$. The participants' mean age was 30.1 years. In univariate analysis, HBV infection was associated with age $>30$ years $(\mathrm{p}<0.001)$, previous injecting drug use $(\mathrm{p}<0.001)$ and previous sharing of needles $(\mathrm{p}<0.001)$. In a logistic regression multivariate model, HBV infection was associated with age $>30$ years $\left(\mathrm{OR}=3.3 ; \mathrm{CI}_{95 \%}: 1.8-6.1\right)$ and previous injecting drug use $\left(\mathrm{OR}=2.7 ; \mathrm{CI}_{95 \%}: 1.9-6.4\right)$. $\mathrm{HBV}$ infection on prisons represents a major health problem, mainly associated with age over 30 years and previous injecting drug use.

Keywords: Hepatitis B. Prisons. Prevalence. Risk fators.

\section{Introdução}

A população prisional é considerada como de alto risco para diferentes infecções, tais como tuberculose, síndrome da imunodeficência adquirida (Aids), hepatite $\mathrm{B}$, hepatite $\mathrm{C}$ e doenças sexualmente transmissíveis (DSTs) em geral. Marginalização social, dependência de drogas ilícitas, baixo nível socioeconômico e precárias condições do sistema de saúde são fatores que facilitam a elevada disseminação dessas doenças entre presidiários ${ }^{1}$.

A partir do início da década de 1970 , alguns estudos começaram a evidenciar proporções mais elevadas de infecção pelo vírus da hepatite B (HBV) nos encarcerados do que na população geral, com taxas de prevalência para o antígeno de superfície (HBsAg) variando de 1,5 a $2,1 \%^{2-4}$. A disponibilização de testes para detecção do anticorpo contra o antígeno do core (anti$\mathrm{HBc}$ ), cuja presença indica infecção natural pelo HBV, confirmou a maior ocorrência de infecção entre prisioneiros, independente da condição de portador do HBsAg.

A hepatite B no sistema carcerário tem sido objeto de estudo em vários países do mundo. Na Inglaterra, foi encontrada uma prevalência de $8 \%$ para o anti- $\mathrm{HBc}^{5}$, enquanto na Itália detectou-se $6,7 \%$ de $\mathrm{HBsAg}^{6}$. Na França, 32\% dos presidiários apresentavam presença de um ou mais marcadores de infecção pelo $\mathrm{HBV}^{7}$. No continente africano, estudo realizado em presidiários de Gana mostrou prevalência de $17,4 \%$ do marcador HBsAg 8 . No Brasil, os poucos estudos publicados revelam valores contrastantes, com percentuais de HBsAg variando de 26,4\%, em Goiânia ${ }^{9}$, a 1,9\%, em Londrina ${ }^{10}$. Presença de qualquer marcador foi observada em 17,5\% dos encarcerados em Manhuaçu (MG) ${ }^{11}$.

Os elevados valores de infecção pelo vírus da hepatite $\mathrm{B}$ entre presidiários sinalizam para a necessidade de programas preventivos voltados a essa população, os quais devem ser instituídos com base no conhecimento da situação epidemiológica e da dinâmica de transmissão. Com vistas 
a contribuir com o sistema penitenciário, o presente trabalho tem como objetivos: estimar a prevalência de exposição do $\mathrm{HBV}$ e investigar seus fatores de risco entre presidiários de Ribeirão Preto, Estado de São Paulo.

\section{Material e Métodos}

A penitenciária de Ribeirão Preto foi escolhida por ser a maior do município e não ter se submetido a investigação semelhante no passado. Este estabelecimento prisional é constituído de quatro pavilhões de regime fechado e um de regime semiaberto, que abrigavam, respectivamente, 893 e 137 presidiários (total de 1.030), em maio de 2003. A população de referência foi representada pela totalidade dos 893 presidiários confinados em regime de prisão fechada, excluindo-se os da ala do semiaberto por este setor se encontrar em área de difícil acesso ao local de aplicação do questionário e coleta de sangue. O cálculo do tamanho amostral mínimo (245 participantes) foi realizado assumindo-se uma soroprevalência para o HBV em presidiários da ordem de $20 \%$, uma precisão de $5 \%$ e um nível de confiança de $95 \%$.

Empregou-se um processo de amostragem casual simples, tendo sido sorteados 100 presos de cada um dos quatro pavilhões de regime fechado. Foram incluídos todos os sorteados que manifestaram concordância em participar da pesquisa mediante assinatura de um termo de consentimento livre e esclarecido, após tomar conhecimento dos objetivos e da metodologia do estudo, e dos principais aspectos da transmissão e evolução de doenças como Aids, hepatite B, hepatite $\mathrm{C}$ e outras DSTs.

Na sala de aplicação de medicamentos foi aplicado a cada participante, face a face, um questionário ${ }^{12}$ com questões fechadas que levantava informações demográficas, tempo de prisão, uso de drogas ilícitas e comportamento sexual. O pesquisador principal, médico com formação em infectologia, obteve todas essas informações. Em seguida, uma amostra de $10 \mathrm{ml}$ de sangue foi colhida de cada participante por uma auxiliar de enfermagem da própria unidade prisional. Os soros resultantes foram submetidos a métodos imunoenzimáticos para detecção dos marcadores HBsAg e antiHBs através do Bioelisa (Biokit, Espanha), e do anti-HBc total, através do Hepanostika anti-HBc UNI-FORM (Biomerieux, França), processados e interpretados segundo as especificações dos fabricantes. A aplicação do questionário e a coleta sanguínea ocorreram de maio a agosto de 2003. Os resultados sorológicos foram fornecidos individualmente pelo pesquisador. Aqueles com resultados indicativos de infecção foram encaminhados para acompanhamento especializado.

Os dados foram inseridos no Programa EPIINFO 6.04 e posteriormente transportados para o pacote estatístico STATA 6.0. Os estudos iniciais de associação foram realizados através da aplicação dos testes qui-quadrado e exato de Fischer. As variáveis que apresentaram um valor de probabilidade igual ou inferior a $0,25^{13}$ foram selecionadas para uma análise multivariada, através de um modelo de regressão logística não condicional.

Este projeto foi aprovado pelo Comitê de Ética em Pesquisa do Hospital das Clínicas da Faculdade de Medicina de Ribeirão Preto da Universidade de São Paulo-USP, processo HCRP no 10166/2002.

\section{Resultados}

Dos 400 presidiários sorteados, 55 recusaram-se a participar do estudo e 345 responderam ao questionário e assinaram o termo de consentimento. Desses, 12 recusaram-se a colher sangue, fazendo com que 333 participassem efetivamente da pesquisa. A idade dos participantes variou de 19 a 69 anos, com média de 30,1 anos e mediana de 28 anos. Mais da metade $(52,9 \%)$ nasceu na cidade de Ribeirão Preto e região, enquanto os nascidos em outras regiões do Estado e em outros Estados representaram percentuais respectivamente iguais a $24,6 \%$ e 22,5\%. Existência de parceira sexual fixa foi 
relatada por $58,0 \%$ dos participantes.

Foram considerados como tendo infecção atual ou pregressa pelo vírus da hepatite B os participantes que apresentaram os seguintes marcadores: HBsAg e anti-HBc total (4 presos); anti-HBc total e anti-HBs (43); HBsAg isolado (8) ou anti-HBc total isolado (10). Assim, 65 presidiários apresentaram positividade a um ou mais marcadores, representando um valor de prevalência total igual a $19,5 \%\left(\mathrm{IC}_{95 \%}: 15,2-23,8\right)$.

A Tabela 1 mostra os participantes e a positividade para hepatite $\mathrm{B}$ de acordo com algumas características e fatores de risco para a infecção. Chama a atenção os percentuais elevados de participantes com tatuagem (36,0\%), antecedente de DST (34,2\%) e relação sexual com usuário de droga ilícita $(45,7 \%)$. Maior presença de marcadores foi observada entre os que referiam tatuagem, transfusão sanguínea, antecedentes de hepatite e de icterícia, uso de preservativo em visita íntima, história de DST e de relação sexual com usuários de drogas ilícitas, porém sem significância estatística. É de se notar que apenas um indivíduo classificou-se como homossexual. Embora não mostrado na tabela, destaca-se que cerca de $80 \%$ dos participantes revelaram uso pregresso ou atual de drogas ilícitas não injetáveis, sem associação estatística com a presença de marcadores de hepatite B.

A distribuição dos positivos ao HBV apresentou tendência crescente de acordo com a idade, atingindo valores mais elevados nos situados acima de 30 anos (agrupando-se os participantes em duas faixas etárias - até 30 anos e acima de 30 anos: $\mathrm{p}<$ $=0,001)$. Destaca-se ainda a forte associação estatística entre resultado positivo ao HBV e as variáveis uso de drogas injetáveis ( $p<0,001)$ e compartilhamento de agulhas ( $\mathrm{p}<0,001)$, apesar da baixa frequência de tais práticas na população estudada $(8,7 \%$ e 3,3\%, respectivamente).

O resultado da análise multivariada é mostrado na Tabela 2. No modelo final, as variáveis idade acima de 30 anos (OR $=3,3 ; \mathrm{IC}_{95 \%}$ : CI $\left.1,8-6,1\right)$ e uso prévio de drogas injetáveis $\left(\mathrm{OR}=2,7 ; \mathrm{IC}_{95 \%}: 1,9-6,4\right)$ mostraram-se capazes de predizer de modo independente a infecção pelo HBV.

\section{Discussão}

O valor de 19,5\% de prevalência para HBV encontrado no presente estudo assemelha-se ao verificado no interior de Minas Gerais $(17,5 \%)^{11}$ e na Fundação CASA, em São Paulo $(16,0 \%)^{14}$, situando-se abaixo do encontrado por Martelli et al. ${ }^{9}$, em prisão de Goiás (26,4\%), e acima do descrito em Londrina $(1,9 \%)^{10}$. Levantamento realizado em 920 presidiários da Casa de Detenção e na Penitenciária do Estado de São Paulo encontrou prevalência de 3,6\% para HBsAg e $32,3 \%$ para anti-HBs; entretanto, estes exames foram realizados em apenas dois quintos dos participantes ${ }^{15}$.

Percentuais mais elevados de infecção prévia ou atual pelo $\mathrm{HBV}$ foram relatados em prisões dos EUA, com valores de $32,8 \%$ na Virgínia ${ }^{16}, 43,0 \%$ em Massachusetts ${ }^{17} \mathrm{e}$ $23,1 \%$ em Rhode Island ${ }^{18}$. Em outras partes do mundo, prevalências para hepatite B também apresentam índices expressivos entre encarcerados, com relatos de $6,2 \%$ em Dublin, na República da Irlanda ${ }^{19}$, e de $4,4 \%$ em Durango, no México ${ }^{20}$.

A prevalência de hepatite B costuma se elevar proporcionalmente à idade. Esta distribuição é observada não apenas entre presidiários, tal como no presente estudo e em prisões inglesas ${ }^{5}$, mas também em estudos populacionais e nas notificações de rotina do sistema de vigilância epidemiológica ${ }^{21}$. Este fato se deve, muito provavelmente, a um acúmulo de riscos ao longo da vida, que se processa de modo ainda mais intenso em populações encarceradas ${ }^{18}$.

Esta somatória de exposições de risco faz também com que presidiários exibam, via de regra, maiores prevalências de DSTs, em comparação com a população geral ${ }^{22}$. A associação de hepatite B com outras DSTs não é relatada na literatura, talvez por não se fazer de forma independente, provavelmente estando associada a outros fatores de risco, como exposição a indivíduos usuários de drogas ilícitas. No presente estudo, a 
Tabela 1 - Distribuição dos participantes e positividade para hepatite B segundo algumas características e fatores de risco para a infecção. Penitenciária de Ribeirão Preto, São Paulo, 2003. Table 1 - Distribution of inmates and Hepatitis B status according to some features and risk factors for infection. Ribeirão Preto Penitentiary, São Paulo, 2003.

\begin{tabular}{|c|c|c|c|c|}
\hline \multirow[t]{2}{*}{ Variável } & \multirow[t]{2}{*}{ Participantes } & \multicolumn{2}{|c|}{$\mathrm{HBV}+$} & \multirow[t]{2}{*}{$\mathrm{p}$} \\
\hline & & $\mathbf{n}$ & $\%$ & \\
\hline Idade & & & & $<0,001$ \\
\hline $19-24$ & 96 & 6 & 6,3 & \\
\hline $25-30$ & 107 & 18 & 16,8 & \\
\hline $31-35$ & 55 & 16 & 29,1 & \\
\hline $36-45$ & 60 & 20 & 33,3 & \\
\hline$>45$ & 15 & 5 & 33,3 & \\
\hline Tatuagem & & & & 0,55 \\
\hline Sim & 120 & 39 & 32,5 & \\
\hline Não & 213 & 26 & 12,2 & \\
\hline Transfusão de sangue & & & & 0,19 \\
\hline Sim & 32 & 9 & 28,1 & \\
\hline Não & 301 & 56 & 18,6 & \\
\hline Antecedente de hepatite & & & & 0,16 \\
\hline Sim & 27 & 8 & 29,6 & \\
\hline Não & 306 & 57 & 18,6 & \\
\hline Antecedente de icterícia & & & & 0,28 \\
\hline Sim & 24 & 7 & 29,2 & \\
\hline Não & 309 & 58 & 18,8 & \\
\hline Preferência sexual & & & & 1,00 \\
\hline Heterossexual & 332 & 65 & 19,2 & \\
\hline Homossexual & 1 & - & - & \\
\hline Uso preservativo em visita íntima & & & & 0,15 \\
\hline Sim & 69 & 16 & 23,2 & \\
\hline Não & 264 & 49 & 18,6 & \\
\hline Antecedente de DST & & & & 0,12 \\
\hline Sim & 114 & 28 & 24,6 & \\
\hline Não & 219 & 37 & 16,9 & \\
\hline Sexo com usuário de droga ilícita & & & & 0,13 \\
\hline Sim & 152 & 35 & 23,0 & \\
\hline Não & 181 & 30 & 16,6 & \\
\hline Uso prévio de drogas injetáveis & & & & $<0,001$ \\
\hline Sim & 29 & 13 & 44,8 & \\
\hline Não & 304 & 52 & 17,1 & \\
\hline Compartilhamento de agulhas & & & & $<0,001$ \\
\hline Sim & 11 & 6 & 54,5 & \\
\hline Não & 322 & 59 & 18,3 & \\
\hline Total & 333 & 65 & 19,5 & \\
\hline
\end{tabular}


Tabela 2 - Resultado do modelo final de regressão logística para variáveis associadas à positividade do HBV. Penitenciária de Ribeirão Preto, São Paulo, 2003.

Table 2 - Result of the final logistic regression model associated to positive HBV. Ribeirão Preto Penitentiary, São Paulo, 2003.

\begin{tabular}{lccc}
\hline Variável & OR & $\mathbf{9 5 \% I C}$ & $\mathbf{p}$ \\
\hline Idade $>30$ anos & 3,3 & $1,8-6,1$ & $<0,001$ \\
Uso prévio de drogas injetáveis & 2,7 & $1,9-6,4$ & 0,020 \\
\hline
\end{tabular}

não ocorrência de tal associação pode ser explicada pelo reduzido número de presidiários que relataram DST do tipo ulcerativa, situação em que a transmissão viral ocorre de modo mais eficiente do que nas lesões não ulcerativas ${ }^{23}$.

Relatos de práticas homossexuais no interior de presídios, inclusive associadas a uso de drogas injetáveis, estão presentes na literatura ${ }^{8,9,11,24}$. A sua virtual inexistência na presente investigação pode ser devida a um viés de resposta, pois o estigma associado ao homossexualismo torna possível o fato de que alguns participantes tenham negado essa prática, mesmo quando ela se faz presente. Entretanto, a mais provável explicação poderia ser buscada em um viés de seleção, traduzido pelo fato de que, na unidade prisional de estudo, os indivíduos com práticas homossexuais (travestis e garotos de programa) tendem a ser colocados na assim chamada "ala do seguro", que abriga os que necessitam de isolamento por questões de segurança e que, por tais razões, não foram incluídos na investigação.

Merece destaque o relato de baixo percentual $(20,7 \%)$ de uso de preservativo na visita íntima. É possível que este achado seja decorrente da idéia de irrestrita confiança em relação a uma companheira que, supostamente, tem somente o próprio presidiário como parceiro. Todavia, em conversas informais, os agentes penitenciários relatam um fato já descrito em prisões da França e da Inglaterra ${ }^{7,25}$, qual seja a presença de prostitutas em dias de visita, mantendo relações para as quais os presos não costumam solicitar preservativos. A não associação com a hepatite B pode sinalizar para o fato de que os participantes desse estudo tenham sido infectados, em sua maioria, antes do encarceramento.

O achado de não associação entre hepatite B e consumo de drogas ilícitas pelas parceiras sexuais dos presidiários já havia sido relatado por Adjei et al..$^{8} \mathrm{em}$ Gana. Na presente investigação, é possível que isso se deva a um predomínio de consumo de drogas não injetáveis por parte das parceiras do encarcerados. Todavia, essa possibilidade não pode ser explorada em decorrência de o questionário utilizado na pesquisa não discriminar a natureza das drogas consumidas.

A triagem sorológica para hepatite B nos bancos de sangue vem sendo adotada no Brasil desde a década de 1970, praticamente eliminando a transmissão da doença por tal mecanismo. Este fato explica a ausência de associação observada entre os presidiários de Ribeirão Preto, cuja idade mediana é inferior a 30 anos.

Tatuagem tem sido descrita como fator de risco para hepatite B quando realizada dentro da própria instituição penal, pois facilita a utilização de aparelhos e objetos com baixo nível de higiene ${ }^{26}$. A não discriminação pelo questionário utilizado nesse estudo acerca do local de realização do processo deixa em aberto a possibilidade de que a falta de associação com a hepatite B aqui observada possa ser devida a um predomínio de tatuagens realizadas fora do ambiente prisional, anteriormente ao encarceramento.

A relativa baixa frequência de manifestações clínicas em casos de hepatite B aguda pode justificar a não associação com antecedentes de icterícia e hepatite percebidos e relatados pelos participantes. Além disso, 
há que se considerar a dificuldade exibida por muitos detentos em compreender o real significado dos termos hepatite e icterícia, fato esse que também pode ter influenciado as respostas fornecidas.

Confirmando inúmeras observações realizadas em prisioneiros em diferentes partes do mundo ${ }^{5,15,19}$, o uso prévio de drogas injetáveis e o compartilhamento de seringas mostraram uma forte associação com a infecção pelo HBV na análise inicial. O modelo de regressão evidenciou a utilização de drogas injetáveis como variável preditora independente do risco de hepatite B, juntamente com idade superior a 30 anos. Apenas 29 indivíduos relataram antecedente de uso de drogas injetáveis (8,7\%), número relativamente reduzido em se tratando de população de presidiários. Percentual ainda menor $(3,3 \%)$ referia compartilhamento de agulhas, o que levanta algumas possíveis explicações. Uma delas refere-se à eventualidade de um viés de informação, consequente à dificuldade de alguns participantes em revelar uma prática associada a comportamentos socialmente marginalizados e legalmente ilícitos. Outra possível explicação seria a substituição do uso de cocaína injetável-muito popular no passado - pelo consumo de crack, que se tornou a maneira predominante de droga adição à cocaína nos últimos anos ${ }^{27}$.

Apesar de a compreensão da dinâmica de transmissão de doenças infecciosas entre presidiários ser fundamental para orientar programas preventivos, chama a atenção a raridade de estudos epidemiológicos em nosso meio voltados a essa população. A despeito dos avanços na sua profilaxia, notadamente a disponibilidade de uma vacina segura, de alta eficácia e baixo preço, a hepatite B continua sendo um problema relevante no sistema prisional brasileiro, exigindo mais atenção no sentido de produzir conhecimentos que orientem a adoção de medidas efetivas de controle.

\section{Referências}

1. Massad E. HIV/AIDS no sistema prisional brasileiro. In: A epidemia de AIDS no Brasil - Situações e Tendências. Ministério da Saúde; 1997: 87-104.

2. Muñiz FJ, Malayska H, Levin WC. An antigen in blood from prisoners. N Engl J Med 1971; 284: 501-2.

3. Kliman A. Australia antigen in volunteers and paid blood donors. N Engl J Med 1971; 284: 109.

4. Krotoski WA. Hepatitis in prisoner blood donors. NEngl J Med 1972; 286: 159.

5. Weild AR, Gill ON, Bennett D, Livingstone SJM, Parry JV, Curran L. Prevalence of HIV, hepatitis B, and hepatitis C antibodies in prisoners in England and Wales: a national survey. Commun Dis Public Health 2000; 3: 121-6.

6. Chiaramonte M, Trivello R, Renzulli G, Zampieri L, Fanecco A, Naccarato R. Hepatitis B virus infection in prisons. A seroepidemiological survey in prisoners and attending staff. J Hyg (Lond) 1982; 89: 53-8.

7. Rotily M, Vernay-vaisse C, Bourliére M, Galinier-Pujol A, Rousseau SO. HBV and HIV screening and hepatitis B immunization programme in the prison of Marseille, France. Int J STD AIDS 1997; 8: 753-9.
8. Adjei AA, Armah HB, Gbagbo F, Ampofo WK, Quaye IKE, Hesse IFA et al. Prevalence of human immunodeficiency virus, hepatitis B virus, hepatitis $C$ virus and syphilis among prison inmates and officers at Nsawam and Accra, Ghana. J Med Microbiol 2006; 55: 593-7.

9. Martelli CM, Andrade Al, Cardoso DD, Sousa LC, Silva SA, Sousa MA et al. soroprevalência e fatores de risco para a infecção pelo vírus da hepatite B pelos marcadores AgHBs e anti-HBs em prisioneiros e primo doadores de sangue. Rev Saúde Pública 1990; 24: 270-6.

10. Jabur A, Baldy JLS, Quesada RMB. AIDS, hepatite B e sífilis: prevalência da infecção em 158 presidiários da cadeia pública de Londrina. Rev Soc Bras Med Trop 1991; 24(S2): 169. [Apresentado no XXVII Congresso da Sociedade Brasileira de Medicina Tropical. Uberaba, 2428 de fevereiro de 1991].

11. Catalan-Soares B, Almeida R, Proietti A. Prevalence of HIV-1/2, HTLV-I/II, hepatitis B virus (HBV), hepatitis $\mathrm{C}$ virus (HCV), Treponema pallidum and Trypanosoma cruzi among prison inmates at Manhuaçu, Minas Gerais State, Brazil. Rev Soc Bras Med Trop 2000; 33: 27-30.

12. Monteiro MR, Passos AD, Figueiredo JF, Gaspar AM, Yoshida CF. Marcadores sorológicos da hepatite B em usuários de um Centro de Testagem para o HIV. Rev Soc Bras Med Trop 2001; 34: 53-9. 
13. Hosmer DW, Lemeshow S. Model-Building strategies and methods for logistic regression. In: Hosmer DW, Lemeshow S. Applied Logistic Regression. New York: John Wiley \& Sons; 1989. pp. 82-134.

14. Carvalho HB, Seibel SD, Burattini MN, Massad E, Reingold A. Vulnerabilidade às infecções pelo HIV, hepatite B e C e sífilis entre adolescentes infratores institucionalizados na Cidade de São Paulo, Brasil. J Bras Doenças Sex Transm 2003; 15: 41-5.

15. Minkoves R. Estudo da soroprevalência da hepatite B em 02 (duas) prisões da Cidade de São Paulo [dissertação de mestrado]. São Paulo: Escola Paulista de Medicina; 1992.

16. Tucker RM, Gaffey MJ, Fisch MJ, Kaiser DL, Guerrant RL, Normansell DE. Seroepidemiology of hepatitis D (delta agent) and hepatitis B among Virginia State prisoners. Clin Ther 1987; 9: 622-8.

17. Barry MA, Gleavy D, Herd K, Schwingl PJ, Werner BG. Prevalence of markers for hepatitis B and hepatitis D in a municipal house of correction. Am J Public Health 1990; 80: 471-3.

18. Macalino GE, Vlahov D, Sanford-Colby S, Patel S, Sabin K, Salas C et al. Prevalence and incidence of HIV, hepatitis $\mathrm{B}$ virus, and hepatitis $\mathrm{C}$ virus infection among males in Rhode Island Prisons. Am J Public Health 2004; 94: 1218-23.

19. Long J, Allwright S, Barry J, Reynolds SR, Thornton L, Bradley F et al. Prevalence of antibodies to hepatitis B, hepatitis $\mathrm{C}$, and HIV and risk factors in entrants to Irish prisons: a national cross sectional survey. BMJ 2001; 323: 1209-13.

20. Alvarado-Esquivel C, Sablon E, Martinez-Garcia S, Estrada-Martinez S. Hepatitis virus and HIV infections in inmates of a state correctional facility in Mexico. Epidemiol Infect 2005; 133: 679-85.
21. Brasil. Ministério da Saúde. Secretaria de Vigilância em Saúde. Sistema de informação de agravos de notificação - SINAN. 2007. Disponível em http://dtr2004.saude.gov. $\mathrm{br} /$ sinanweb/. [Acessado em abril de 2009].

22. Weinbaum CM, Sabin KM, Santibanez SS. Hepatitis B, Hepatitis C and HIV in correctional populations: a review of epidemiology and prevention. AIDS 2005; 19 (S3): 41-6.

23. Atkins M, Nolan M. Sexual transmission of hepatitis B. Curr Opin Infect Dis 2005; 18: 67-72.

24. Gore SM, Bird AG, Hutchinson SJ. Injector-inmates and anal sex with another man in prison. Int J STD AIDS 1998; 9: 781.

25. Green J, Heuston J, Whiteley C, Strang J. Heterosexual activity of male prisoners in England and Wales. Int $J$ STD AIDS 2003; 14: 248-52.

26. Tsang THF, Horowitz E, Vugia DJ. Transmission of hepatitis $\mathrm{C}$ through tattooing in a United States Prison. Am J Gastroenterol 2001; 96: 1304-5.

27. Mesquita F, Kral A, Reingold A, Bueno R, Trigueiros D, Araujo PJ et al. Trends of HIV infection among injection drug users in Brazil in the 1990's: the impact of changes in patterns of drug use. J Acquir Immune Defic Syndr 2001; 28: 298-302.

Recebido em: 19/11/08 Versão final reapresentada em: 30/04/09 Aprovado em: 04/05/09 